\title{
ANALISIS BIAYA, PENDAPATAN DAN EFISIENSI USAHATANI SAYURAN DATARAN TINGGI DENGAN BERBAGAI POLA TANAM DI DESA SUMBER URIP KECAMATAN SELUPU REJANG KABUPATEN REJANG LEBONG
}

\author{
Redy Badrudin ${ }^{1}$ \\ Bambang Sumantri ${ }^{1}$ \\ Edi Paris ${ }^{3)}$ \\ 1 Staff Pengajar Jurusan Sosial Ekonomi Pertanian Fak. Pertanian UNIB \\ ${ }^{2}$ Alumni Jurusan Sosial Ekonomi Pertanian Fak. Pertanian UNIB
}

\begin{abstract}
This research was aimed at estimating production cost, income and economic eficiency of various patterns of high land vegetables farming. This research was carried out on August until September 2004 in Sumber Urip village subdistrict Selupu district of Rejang Lebong. Stratified Random Sampling with equal alocation of 63 respondents was apllied. These respondents then be stratified into 7 strata based on their cultivation patterns. This research resulted the highest the average total cost of monoculture patterns is farmed with cabbage pattern while for polyculture pattern is cabbage inter cultivated with onion leaves The highest income on the monoculture crop pattern, is cauliflower cultivation with onion leaves is the highest for policultuere the highest eficiency for monoculture pattern of cultivate was on cauliflower and for polyculture is onion leafes farming .
\end{abstract}

Keywords : Cost, Income, Eficiency, High-Land Vegetables.

\section{PENDAHULUAN}

Indonesia adalah negara agraris, hal ini ditunjukkan dengan sebagian besar rumah tangga di Indonesia menggantungkan hidupnya di sektor pertanian, yang mengalami peningkatan dari 20,8 juta pada tahun 1993 menjadi 25,6 juta pada tahun 2003, dengan rata-rata pertumbuhan sebesar 2,10\% persen pertahun ( BPS, Februari 2004). Rumah tangga yang bekerja di sektor pertanian tersebut, sebagian besar tinggal diwilayah pedesaan. Menurut Soestrisno (2002) dalam Mukhlis (2003), penduduk Indonesia yang tinggal di wilayah pedesaan tingkat pendapatannya relatif rendah jika dibandingkan dengan penduduk yang tinggal di perkotaan.

Perbedaan pendapatan tersebut berkaitan erat dengan produktivitas para petani Indonesia yang tidak lepas dari berbagai faktor, antara lain luas lahan yang dimiliki, kebijakan pemerintah dalam hal pemberian insentif kepada petani dan sebagainya (Soestrisno (2002) dalam Mukhlis ,2003).

Untuk meningkatkan pendapatan petani, pemerintah Indonesia melakukan diversifikasi pangan, komoditi hortikultura semakin berpeluang untuk dikembangkan Selain itu komoditi 
hortikultura memiliki potensi produksi dan potensi pasar, hal ini didasari oleh meningkatnya permintaan masyarakat terhadap komoditi ini baik dalam kualitas maupun kuantitas. Peningkatan tersebut diakibatkan oleh adanya ; 1) peningkatan jumlah penduduk, 2) peningkatan pendapatan nasional, 3) peningkatan pengetahuan yang mendorong meningkatnya kesadaran masyarakat akan manfaat gizi (Palungkun dan Budiarti (1992) dalam Kasriani, 2003 ).

Tanaman sayuran sebagai bagian dari sub sektor hortikultura dapat dikategorikan sebagai bahan makanan yang vital karena mengandung zat pembangun tubuh serta mengatur proses dalam tubuh, berupa air, mineral dan vitamin. Selain itu sayuran memiliki nilai ekonomi yang dapat berguna untuk meningkatkan pendapatan petani bahkan sebagai sumber devisa negara. Baik sayur - sayuran dataran rendah maupun dataran tinggi adalah merupakan hasil pertanian yang dikonsumsi oleh masyarakat pada hampir semua tingkat umur.

Di Propinsi Bengkulu, tanaman sayur-sayuran banyak dihasilkan di Kabupaten Rejang Lebong, karena daerah ini merupakan daerah dengan keadan iklimnya yang sesuai tanaman sayursayuran(Sumber : Kantor Pengolahan Data Elektronik, PEMPROP Bengkulu. 2004). Sumber Urip adalah salah satu wilayah yang terletak di kecamatan Selupu Rejang kabupaten Rejang Lebong yang memiliki potensi sub sektor hortikultura yaitu sayuran cukup besar dalam upaya meningkatkan kondisi sosial ekonomi masyarakatnya. Sebagai salah satu daerah penghasil sayur-sayuran di Propinsi Bengkulu, petani di Desa Sumber Urip terus berupaya meningkatkan produktivitasnya dengan melakukan berbagi pola tanam di antaranya melakukan kombinasi jenis tanaman yang ditanamnya

Namun seperti pada umumnya petani di Indonesia, petani di Desa Sumber Urip juga dihadapkan pada suatu masalah yaitu terbatasnya lahan, dimana rata-rata kepemilikan luas lahan oleh petani tergolong sempit. Selain itu petani juga memiliki modal usahatani yang terbatas, disamping manajemen atau pengelolaan usahatani yang belum maksimal.

Tujuan pengelolaan usahatani pada dasarnya adalah memilih berbagai alternatif penggunaan sumber daya yang terbatas yang meliputi lahan, tenaga kerja, modal, waktu dan pengelolaan. Hal ini dimaksudkan untuk mencapai tujuan yang sebaik-baiknya dalam lingkungan yang penuh resiko dan kesulitan-kesulitan yang harus dihadapi dalam menjalankan usahataninya. 
Produksi suatu jenis sayuran dan pendapatan yang diterima oleh petani tidak hanya ditentukan oleh teknologi untuk memproduksi jenis sayuran tersebut, tetapi juga sangat dipengaruhi oleh tanaman lain di dalam pola pertanaman yang dipilh oleh petani untuk lahannya. (Bahar dan Rianti, (1991) dalam Darwin A., dkk. 1996). Salah satu cara untuk meningkatkan pendapatan petani adalah melakukan perbaikan kegiatan usahataninya dengan merangkum berbagai alternatif cabang usahatani dalam suatu proses produksi pertanian. Perbaikan ini dilakukan dengan mengalokasikan sumber daya terbatas yang dikuasai petani secara optimal sesuai dengan kondisi dan potensi daerah. ( Kasriani, 2003).

Berdasarkan uraian latar belakang di atas maka penelitian ini bertujuan untuk menghitung besar biaya yang dikeluarkan oleh petani dan pendapatan yang diterima oleh petani serta bagaimana efisiensi dari usahatani sayuran dataran tinggi pada berbagai pola tanam di Desa Sumber Urip dan mengetahui pola tanam yang paling efisien ? Dalam penelitian ini, hanya menghitung dan menganalisis; biaya, pendapatan dan efisiensi riil usahatani sayuran dataran tinggi dengan berbagai pola tanam, adapun pola tanamnya dibatasi hanya pada tujuh pola tanam yang dominan diusahakan di daerah penelitian, yang terdiri dari: pola tanam kubis monokultur, sawi monokultur, bawang daun monokultur, kubis bunga monokultur, tumpang sari antara sawi dengan bawang daun, tumpang sari kubis dengan bawang daun, dan tumpang sari kubis bunga dengan bawang daun.

\section{METODE PENELITIAN}

\section{Metode Penentuan Lokasi dan Responden}

Penentuan lokasi penelitian dilakukan secara sengaja (Purposive) di Desa Sumber Urip karena merupakan daerah dataran tinggi serta salah satu daerah sentra produksi tanaman hortikultura di kabupaten Rejang Lebong. Populasi dalam penelitian ini adalah petani yang berusahatani sayuran dataran tinggi dengan berbagai pola tanam, yang tinggal dan memiliki lahan garapan di Desa Sumber Urip sebanyak 544 petani . Dengan pertimbangan perbedaan antara petani yang memproduksi sayuran dataran tinggi dengan berbagai pola tanam, baik yang monokultur maupun yang polikultur 
maka pengambilan sampel dilakukan secara bertingkat (Stratified Random Sampling) dengan alokasi berimbang dengan menggunakan sampling fraction.

Untuk menentukan jumlah sampel dihitung dulu variance dari masing-masing populasi pada masing-masing strata, sedangkan menentukan alokasi sampel yang berimbang dengan besarnya strata maka digunakan rumus sampling fraction. Berikutnya di dapat ditentukan besarnya sampel berdasarkan pendekatan Nazir, 1999.Jumlah strata, populasi serta sampel pada masing-masing strata disajikan pada Tabel 1.

Tabel 1. Jumlah Populasi sub populasi dan Petani Responden Tanaman Sayuran Dataran Tinggi dengan Berbagai Pola Tanam di Desa Sumber Urip Kecamatan Selupu Rejang Kabupaten Rejang Lebong

\begin{tabular}{|c|c|c|}
\hline Strata (Kode) & $\begin{array}{l}\text { Jumlah } \\
\text { populasi }\end{array}$ & $\begin{array}{c}\text { Jumlah } \\
\text { Responden }\end{array}$ \\
\hline I. Petani yang berusahatani kubis secara monokultur $(\mathrm{A})$. & 163 & 19 \\
\hline II. Petani yang berusahatani sawi secara monokultur (B). & 109 & 13 \\
\hline III. Petani yang berusahatani bawang daun secara monokultur (C). & 82 & 10 \\
\hline IV. Petani yang berusahatani kubis bunga secara monokultur (D). & 54 & 6 \\
\hline V. Petani yang berusahatani sawi dan bawang daun secara tumpang sari $(\mathrm{E})$. & 54 & 6 \\
\hline VI. Petani yang berusahatani kubis dan bawang daun secara tumpang sari $(\mathrm{F})$. & 38 & 4 \\
\hline $\begin{array}{l}\text { VII. VII. Petani yang berusahatani kubis bunga dan bawang daun secara } \\
\text { tumpang sari }(G) \text {. }\end{array}$ & 44 & 5 \\
\hline Jumlah & 544 & 63 \\
\hline
\end{tabular}

Sumber : Hasil Survey, Agustus 2004

\section{Metode Analisis Data}

Dalam analisis kualitatif ini dilakukan secara deskriptif, yaitu dengan membuat uraian data secara sistematis , faktual dan akurat, kemudian dicari hubungan antara suatu gejala dengan gejala lainnya yang berhubungan dengan hasil penelitian. Analisis biaya ditujukan untuk menilai biaya yang harus dikeluarkan dalam usahatani sayuran dataran tinggi dengan berbagai pola tanam Sedangkan analisis pendapatan ditujukan untuk menilai tingkat pendapatan petani. Untuk mengukur efisiensi usahatani sayuran dataran tinggi dengan berbagai pola tanam digunakan analisis $\mathrm{R} / \mathrm{C}$ ratio (Revenue Cost Ratio). Berdasarkan rumus di atas dapat diketahui untung, impas (tidak untung dan tidak rugi), dan rugi suatu usahatani.

\section{HASIL DAN PEMBAHASAN}


ISSN 1412 - 8837

\section{Analisis Total Biaya Riil}

Biaya total usahatani merupakan penjumlahan dari semua biaya yang dikeluarkan dalam satu kali musim tanam. Biaya usahatani sayuran dataran tinggi terdiri dari biaya tetap (fixed cost) dan biaya tidak tetap (variable cost). Rata - rata biaya tetap yang dikeluarkan petani pada usahatani sayuran dataran tinggi dapat dilihat pada Tabel 2.

Tabel 2. Rata-rata biaya Tetap Usahatani sayuran dataran Tinggi dengan Berbagai Pola Tanam di Desa Sumber Urip Kecamatan Selupu Rejang Kabupaten Rejang Lebong

\begin{tabular}{cccc}
\hline \multirow{2}{*}{ Pola Tanam } & Luas Tanam & \multicolumn{3}{c}{ Rata-rata Biaya } \\
\cline { 2 - 4 } & $(\mathrm{Ha})$ & $(\mathrm{Rp} / \mathrm{ut} / \mathrm{MT})$ & $(\mathrm{Rp} / \mathrm{Ha} / \mathrm{MT})$ \\
\hline A & 0,27 & 531,58 & 2.000 \\
B & 0,25 & 378,46 & 1.500 \\
C & 0,24 & 305,00 & 1.250 \\
D & 0,37 & 733,33 & 2.000 \\
E & 0,19 & 280,00 & 1.500 \\
F & 0,29 & 580,00 & 2.000 \\
G & 0,26 & 516,00 & 2.000 \\
\hline
\end{tabular}

Sumber: Data Primer diolah, 2004

Besar kecilnya biaya tetap (pajak) pada masing-masing pola tanam dipengaruhi luas lahan yang dimiliki.

\section{Biaya tidak tetap (variable cost)}

Biaya tidak tetap meliputi biaya benih, pupuk, pestisida, dan biaya tenaga kerja. Rata - rata biaya tidak tetap yang dikeluarkan petani pada usahatani sayuran dataran tinggi dapat dilihat pada Tabel 3 berikut ini.

Tabel 3. Rata-rata biaya Tidak Tetap Usahatani Sayuran Dataran Tinggi dengan Berbagai Pola Tanam di Desa Sumber Urip Kecamatan Selupu Rejang Kabupaten Rejang Lebong

\begin{tabular}{cccc}
\hline \multirow{2}{*}{ Pola Tanam } & Luas Tanam & \multicolumn{2}{c}{ Rata-rata Biaya } \\
\cline { 2 - 4 } & $(\mathrm{Ha})$ & $(\mathrm{Rp} / \mathrm{ut} / \mathrm{MT})$ & $(\mathrm{Rp} / \mathrm{Ha} / \mathrm{MT})$ \\
\hline A & 0,27 & $602.789,47$ & $2.267 .920,79$ \\
B & 0,25 & $482.019,23$ & $1.910 .442,07$ \\
C & 0,24 & $194.010,00$ & $1.506 .335,42$ \\
D & 0,37 & $577.883,33$ & $1.576 .045,45$ \\
E & 0,19 & $325.550,00$ & $1.744 .017,86$ \\
F & 0,29 & $699.295,83$ & $2.411 .364,94$ \\
\hline
\end{tabular}

Analisis Biaya, Pendapatan dan Efisiensi Usahatani Sayuran Dataran Tinggi .......(Redy B, Bambang S, Edi P) 
ISSN 1412 - 8837

\begin{tabular}{cccc}
\hline G & 0,26 & $812.350,00$ & $3.148 .643,41$ \\
\hline Sumber : Data Primer diolah, 2004 & &
\end{tabular}

Besar kecilnya biaya tidak tetap pada masing-masing pola tanam disebabkan oleh luas lahan, jumlah benih/bibit, pupuk, pestisida, dan tenaga kerja yang digunakan, serta kemampuan petani dalam memenuhi sarana produksi tersebut. Dari penjelasan kedua biaya tersebut, maka besarnya rata-rata total biaya pada masing-masing pola tanam dapat dilihat pada Tabel 4 berikut ini.

Tabel 4. Rata-rata Total Biaya Usahatani Sayuran Dataran Tinggi dengan Berbagai Pola Tanam di Desa Sumber Urip Kecamatan Selupu Rejang Kabupaten Rejang Lebong

\begin{tabular}{cccc}
\hline \multirow{2}{*}{ Pola Tanam } & Luas Lahan & \multicolumn{2}{c}{ Total Biaya } \\
\cline { 2 - 4 } & $(\mathrm{Ha})$ & $603.321,05$ & $(\mathrm{Rp} / \mathrm{Ha} / \mathrm{MT})$ \\
\hline A & 0,27 & $482.365,38$ & $2.269 .920,79$ \\
B & 0,25 & $353.300,00$ & $1.911 .814,02$ \\
C & 0,24 & $578.616,67$ & $1.447 .950,82$ \\
D & 0,37 & $325.830,00$ & $1.578 .045,45$ \\
E & 0.19 & $699.875,83$ & $1.745 .517,86$ \\
F & 0.29 & $812.866,00$ & $2.413 .364,94$ \\
G & 0,26 & & $3.150 .643,41$ \\
\hline
\end{tabular}

Sumber : Data Primer diolah, 2004

Total biaya didapat dari penjumlahan antara biaya tetap dengan biaya variabel. Besar kecilnya biaya yang dikeluarkan pada masing-masing pola tanam disebabkan oleh besar kecilnya penggunaan faktor produksi. Selain itu juga faktor keadaan tanah dan kombinsai tanaman, yang dapat mempenagruhi penggunaan input seperti pupuk, benih, pestisida dan tenaga kerja.

\section{Produksi}

Tinggi rendahnya produksi pertanian antara lain ditentukan oleh tingkat penerapan teknologi pertanian. Salah satu indikatornya adalah penggunaan sarana produksi seperti benih, pupuk, pestisida. Produksi disini adalah produksi yang dijual oleh petani, yang dihasilkan pada satu kali musim tanam Mei 2004 - Agustus 2004. Rata-rata produksi dan penerimaan dapat dilihat pada Tabel 5.

Tabel 5. Rata-rata Produksi yang dijual pada Usahatani Sayuran Dataran Tinggi dengan Berbagai Pola Tanam di Desa Sumber Urip Kecamatan Selupu Rejang Kabupaten Rejang Lebong

\begin{tabular}{ccccccc}
\hline Pola & \multicolumn{3}{c}{ Komoditi } & \multicolumn{2}{c}{ Total } \\
\cline { 2 - 7 } Tanam & Kubis $(\mathrm{Kg})$ & Sawi $(\mathrm{Kg})$ & Bawang daun $(\mathrm{Kg})$ & Kubis Bunga $(\mathrm{Kg})$ & $(\mathrm{Kg})$ & $(\mathrm{Kg})$ \\
\hline
\end{tabular}


ISSN 1412 - 8837

\begin{tabular}{|c|c|c|c|c|c|c|c|c|c|c|}
\hline & ut & $\mathrm{Ha}$ & Ut & $\mathrm{Ha}$ & Ut & $\mathrm{Ha}$ & Ut & $\mathrm{Ha}$ & ut & $\mathrm{Ha}$ \\
\hline$A$ & 10.642 & 40.040 & & & & & & & 10.642 & 40.040 \\
\hline B & & & 6.539 & 23.352 & & & & & 6.539 & 25.915 \\
\hline C & & & & & 1.640 & 6.721 & & & 1.640 & 6.721 \\
\hline D & & & & & & & 3.250 & 8.864 & 3.250 & 8.864 \\
\hline$E$ & & & 2.600 & 18.571 & 817 & 17.500 & & & 3.417 & 36.389 \\
\hline $\mathrm{F}$ & 8.000 & 36.782 & & & 1.100 & 15.172 & & & 9.100 & 53.056 \\
\hline G & & & & & 1.200 & 18.605 & 1.920 & 9.923 & 3.120 & 28.386 \\
\hline
\end{tabular}

Sumber : Data Primer diolah, 2004

Besar kecilnya produksi dipengaruhi antara lain oleh penggunaan faktor produksi seperti bibit, selain itu juga dipengaruhi oleh pola tanam yang dilakukan dan luas tanam untuk masing-masing komoditi pada pola tanam yang diusahakan.

\section{Penerimaan Riil}

Penerimaan riil dapat diketahui dengan mengalikan jumlah produksi yang dijual dengan harga jual dari masing-masing komoditi. Dalam penelitian ini penerimaan yang dimaksud adalah penerimaan yang diperoleh dari hasil penjualan kubis, sawi, bawang daun, dan kubis bunga.

Tabel 6. Rata-rata Penerimaan Usahatani Sayuran Dataran Tinggi dengan Berbagai Pola Tanam di Desa Sumber Urip Kecamatan Selupu Rejang Kabupaten Rejang Lebong

\begin{tabular}{|c|c|c|c|}
\hline \multirow{2}{*}{ Pola tanan } & \multirow{2}{*}{$\frac{\text { Luas Tanam }}{(\mathrm{Ha})}$} & \multicolumn{2}{|c|}{ Penerimaan (Rp) } \\
\hline & & Ut/MT & $\mathrm{Ha} / \mathrm{MT}$ \\
\hline$A$ & 0,27 & $532.105,26$ & $2.001 .980,20$ \\
\hline B & 0,25 & $2.323 .076,92$ & $9.207 .317,07$ \\
\hline C & 0,24 & $1.114 .000,00$ & $4.565 .573,77$ \\
\hline D & 0,37 & $5.800 .000,00$ & $15.818 .181,82$ \\
\hline$E$ & 0,19 & $1.759 .166,67$ & $9.424 .107,14$ \\
\hline $\mathrm{F}$ & 0,29 & $1.196 .250,00$ & $4.125 .000,00$ \\
\hline G & 0,26 & $4.304 .000,00$ & $16.682 .170,54$ \\
\hline
\end{tabular}

Sumber : Data Primer diolah, 2004

Selain produksi, penerimaan juga dipengaruhi oleh harga. Menurut Sudaryanto (1993) dan Adiyoga dan Hardijanto (1996) dalam Irawan, (2003) fluktuasi harga produk hortikultura terutama jenis tanaman jenis sayuran, relatif tinggi. Kondisi demikian pada dasarnya terjadi akibat kelebihan 
atau kekurangan penawaran dibandingkan permintaan. Fluktuasi harga tersebut pada umumnya disebabkan oleh dissinkronisasi perencanaan produksi antar daerah produsen. Faktor lain yang dapat berperan adalah keterbatasan peralatan penyimpanan yang mampu mengendalikan volume penawaran, sesuai dengan kebutuhan konsumen. Fluktuasi harga tersebut sering kali lebih merugikan petani daripada pedagang, karena petani memiliki potensi yang lebih lemah, oleh karena itu dapat dipahami jika keuntungan pedagang dalam tataniaga sayuran relative tinggi, berkisar antara 14 persen hingga 50 persen dari harga tingkat konsumen.

Perbedaan besarnya produksi yang dihasilkan disebabkan antara lain faktor penerapan teknologi , luas lahan, kesuburan lahan dan pola tanam yang diusahakan.

\section{Pendapatan Riil}

Pendapatan adalah selisih antara penerimaan dengan total biaya riil yang dikeluarkan dari usahatnai sayuran dataran tinggi dengan bebagai pola tanam. Pendapatan usahatani sangat ditentukan oleh penerimaan dari produksi yang dihasilkan. Untuk lebih jelas mengenai pendapatan dan efisiensi dapat dilihat pada Tabel 7 berikut ini.

Tabel 7. Rata-rata Pendapatan dan Efisiensi Riil Usahatani Sayuran Dataan Tinggi Dengan Berbagai Pola Tanam di Desa Sumber Urip Kecamatan Selupu Rejang Kabupaten Rejang Lebong

\begin{tabular}{cccccc}
\hline \multirow{2}{*}{ Pola Tanam } & Luas Tanam & \multicolumn{2}{c}{ Rata-Rata Pendapatan Riil } & \multicolumn{2}{c}{ Rata-rata R/C ratio Riil } \\
\cline { 2 - 4 } & $(\mathrm{Ha})$ & Rp/Ut/MT & Rp/ Ha/MT & (ut/MT) & (Ha/MT) \\
\hline A & 0,27 & $-71.215,79$ & $-267.940,59$ & 0,9 & 0,9 \\
B & 0,25 & $1.840 .711,54$ & $7.295 .503,05$ & 4,8 & 4,8 \\
C & 0,24 & $919.685,00$ & $3.769 .200,82$ & 5,7 & 5,7 \\
D & 0,37 & $5.221 .383,33$ & $14.240 .136,36$ & 10,0 & 10,0 \\
E & 0,19 & $1.433 .336,67$ & $7.678589,29$ & 5,4 & 5,4 \\
F & 0,29 & $496.374,17$ & $10.271 .365,57$ & 1,7 & 5,0 \\
G & 0,26 & $3.491 .134,00$ & $26.590 .573,96$ & 5,3 & 8,9 \\
\hline
\end{tabular}

Sumber : Data Primer diolah, 2004

Pendapatan merupakan salah satu indikator keberhasilan petani dalam usahtaninya. Berdasarkan Tabel 7 diketahui bahwa petani pada pola tanam A (kubis) mengalami kerugian, ini disebabkan oleh rendahnya harga komoditi kubis pada saat penelitian. Rendahnya harga kubis saat 
itu dikarenakan di saat produksi , para pedagang pengumpul (toke) di daerah penelitian membeli produk kubis di daerah lain seperti Kabupaten Kerinci, dengan demikian nilai tawar dari produk kubis di daerah penelitian khususnya dan di daerah Rejang Lebong menurun.

\section{Efisiensi Riil Usahatani}

Dari Tabel 7, diketahui bahwa pola tanam A (kubis monokultur) mengalami inefisiensi (rugi), hal ini terjadi di mana penerimaan yang dihasilkan lebih kecil dari biaya yang digunakan. Kondisi ini terjadi karena di saat masa produksi, terjadi penurunan permintaan kubis oleh para pedagang pengumpul (toke), di samping itu pedagang pengumpul (toke) membeli produk dari daerah lain seperti kabupaten Kerinci, Jambi , dengan demikian harga jual produk ini di daerah penelitian khususnya dan daerah Rejang Lebong mengalami penurunan (pada musim sebelumnya harga kubis berkisar antara Rp. 250 - 300,- / kilogram, pada musim ini harga jual kubis hanya Rp. 50,-/Kg).

Pola tanam B telah efisien, Kondisi ini di sebabkan tidak adanya pengurangan permintaan komoditi ini oleh pedagang pengumpul (toke) sehingga nilai jualnya tidak mengalami penurunan (harga musim sebelumnya sama dengan musim sekarang berkisar antara Rp. 200 - 500/ kilogram). Kondisi yang sama juga dialami oleh petani pada pola tanam C (bawang daun monokultur), dimana petani tidak mengeluarkan biaya untuk biaya bibit, sehingga biaya yang dikeluarkan oleh petani menjadi lebih kecil.

Pada pola tanam D (kubis bunga monokultur) telah mencapai efisien, tingginya nilai penerimaan yang di dapat oleh petani disebakan oleh tingginya harga jual komoditi ini ( berkisar Rp. 1.600 - 2.000 / kilogram). Tingginya nilai jual disebabkan oleh nilai gizi yang dikandung kubis bunga dapat dikatakan istimewa terutama kandungan mineralnya, selain itu komoditi ini merupakan komoditi ekspor, Indonesia sudah mengekspor kubis bunga ke Hongkong, Jepang, Singapura, dan Brunai Darussalam (Anonim, 2005).

Pola tanam E (tumpang sari sawi dengan bawang daun) telah efisien. Hal ini disebabkan petani tidak mengeluarkan biaya untuk bawang daun, karena bibit disediakan dari hasil panen sebelumnya sehingga petani hanya mengeluarkan biaya untuk benih sawi saja, yang mengakibatkan biaya yang dikeluarkan menjadi lebih kecil dibandingkan dengan penerimaan yang didapat oleh petani. 
Pada pola tanam $\mathrm{F}$ (tumpang sari kubis dengan bawang daun) juga telah efisien. Dimana kerugian untuk komoditi kubis dapat ditutupi oleh penerimaan yang didapat dari komoditi bawang daun, dengan demikian penerimaan yang didapat oleh petani lebih besar dari biaya yang dikeluarkan. Pola tanam G (tumpang sari kubis bunga dengan bawang daun) telah efisien. Tingginya harga jual untuk komoditi kubis bunga dan rendahnya biaya yang dikeluarkan untuk komoditi bawang daun meneyebabkan penerimaan yang didapat oleh petani lebih besar dibandingkan dengan biaya yang dikeluarkan pada pola tanam ini.

\section{KESIMPULAN DAN SARAN}

\section{Kesimpulan}

Berdasarkan hasil penelitian dan pembahasan dapat ditarik suatu kesimpulan sebagai berikut :

1. Biaya rata-rata usahatani syuran dataran tinggi untuk pola tanam monokultur terbesar pada pola tanam kubis dan terkecil pada pola tnam bawang daun, sedangkan pada pola tanam tumpang sari biya terbesar pada pola tanam tumpang sari kibis bunga dengan bawang daun dan terkecil pada pola tanam tumpang sari sawi dengan bawang dau.

2. Pendapatan rata-rata terbesar untuk pola tanam monokultur pada pola tanam kubis bunga dan terkecil pada pola tanam kubis, sedangkan pada pola tanam tumpang sari terbesar pada pola tanam tumpang sari kubis bunga dengan bawang daun dan terkecil pada pola tanam tumpang sari sawi dengan bawang daun.

3. Pada usahatani sayuran dataran tinggi, untuk pola tanam monokultur yang mempunyai efisiensi yang tinggi adalah pola tanam bawang dun, sedangkan pada pola tanam poli kultur (tumpang sar) adalah pola tanam tumpang sari sawi dengan bawang daun.

\section{Saran}

1. Berdasarkan hasil penelitian ini, sebaiknya petani menanam kubis bunga secara monokultur, karena tanaman ini memberikan pendapatan serta nilai efisiensi yang lebih besar dari pola tanam yang lain.

2. Untuk petani pola tanaman kubis monokultur, sebaiknya untuk melakukan perencanaan yang tepat dalam berusahatani, dengan memperhatikan penawaran komoditi sayuran di pasaran. Sehingga harga jual dari komoditi tidak mengalami fluktuasi yang tinggi.

\section{DAFTAR PUSTAKA}


Bambang Irawan. 2003. Membangun Hortikultura Terintegrasi Dengan Basis Kawasan Pasar. Forum Penelitian Agro Ekonomi 21 (3): 71.

Biro Pusat Statistik.2004. Berita Resmi Statistik No.14/VII/16 Februari 2004. www.bps.go.id

Cornelis, T. 1989. Bimbingan Praktis Pola Tanam Pada Lahan Kering. CV. ARMICO, Bandung.

Dorojatun Kuntjoro Djakti. 2 April 2004. Dana Kemiskinan Mencapai Rp. 18 Triliun. Harian TEMPO. www.ict4pr.org

Darwin, A, dkk.. 1996. Pola Tanam Tumpang sari pada tanaman Kubis. Jurnal Hortikultura 6 (3) : $42-$ 53.

Hernanto, F.. 1989. IImu Usahatani. Penebar Swadaya, Jakarta.

Kasriani. 2002. Analisa Optimalisasi Keuntungan pada Berbagai Pola Usahatani Tanaman Sayuran (Studi Kasus di Kelurahan Padang Harapan Kecamatan Gading Cempaka Kota Bengkulu. Skripsi Fakultas Pertanian, Universitas Bengkulu. (tidak dipublikasikan).

Kantor Pengolahan Data Elektronik Pemerintahan Propinsi Bengkulu. 2005. Potensi Sumber Daya Alam Bengkulu.www.bengkulu.co.id

Mohlis. 1990. Dasar Pemetaan Pola Tanam di Lahan Kering. Laporan Penelitian Fakultas pertanian, Universitas Mataram.

Mukhlis. 2003. Analisa Sikap dan Perilaku Petani Terhadap Pestisida AGRIMEC 18 EC PT. Syngenta Jakarta di Desa Sumber Urip Kecamatan Selupu Rejang Kabupaten Rejang Lebong. Skripsi Fakultas pertanian, Universitas Bengkulu. (tidak dipublikasikan).

Nazir, M. 1999. Metode Penelitian . Ghalia Indonesia .Jakarta

Nelawati. 1997. Permintaan Sayuran Segar Pada Hotel-hotel Berbintang di Propinsi Daerah Istimewa Yogyakarta. Buletin IImiah INSTIPER Yogyakarta 4 (1)

Setiadi. 1984. Hortikultura, Pekarangan dan Buah-buahan. Yasaguna, Jakarta.

Soekartawi.1987. Prinsip Dasar Ekonomi Pertanian. Teori dan aplikasinya. PT. Rajawali Press. Jakarta

1995. Analisis IImu Usahatani. Rajawali Press, Jakarta.

2002. Prinsip Dasar Ekonomi Pertanian . PT. Raja Grafindo Persada. Jakarta

Sunardi, Mulyanti. 1985. Kemiskinan dan Kebutuhan Pokok. CV.Rajawali. Jakarta.

Analisis Biaya, Pendapatan dan Efisiensi Usahatani Sayuran Dataran Tinggi ....... Redy B, Bambang S, Edi P) 